\title{
Galectin-9 suppresses the proliferation of gastric cancer cells in vitro
}

\author{
JITSUKO TAKANO $^{1}$, ASAHIRO MORISHITA ${ }^{1}$, SHINTARO FUJHARA $^{1}$, HISAKAZU IWAMA ${ }^{2}$, \\ FUYUKO KOKADO $^{1}$, KEIKO FUJIKAWA ${ }^{1}$, KOJI FUJITA ${ }^{1}$, TAIGA CHIYO ${ }^{1}$, TOMOKO TADOKORO ${ }^{1}$, \\ TEPPEI SAKAMOTO ${ }^{1}$, TAKAKO NOMURA ${ }^{1}$, JOJI TANI ${ }^{1}$, HISAAKI MIYOSHI ${ }^{1}$, HIROHITO YONEYAMA ${ }^{1}$, \\ HIDEKI KOBARA $^{1}$, HIROHITO MORI ${ }^{1}$, TOSHIHIRO NIKI ${ }^{3}$, MITSUOMI HIRASHIMA $^{3}$ and TSUTOMU MASAKI ${ }^{1}$ \\ ${ }^{1}$ Department of Gastroenterology and Neurology, ${ }^{2}$ Life Science Research Center and ${ }^{3}$ Department of Immunology \\ and Immunopathology, Kagawa University School of Medicine, Kagawa 761-0793, Japan
}

Received September 17, 2015; Accepted October 26, 2015

DOI: $10.3892 /$ or.2015.4452

\begin{abstract}
Gastric cancer is the second-leading cause of cancer-related mortality worldwide, and the prognosis of advanced gastric cancer remains poor. Galectin-9 (Gal-9) is a tandem-repeat-type galectin that has recently been demonstrated to exert anti-proliferative effects on various types of cancer cells. The aim of our present study was to evaluate the effects of Gal-9 on human gastric cancer cells and the expression levels of microRNAs (miRNAs) associated with the antitumor effects of Gal-9 in vitro. In our initial experiments, Gal-9 suppressed the proliferation of gastric cancer cell lines in vitro. Our data further revealed that Gal-9 increased caspase-cleaved keratin 18 (CCK18) levels in gastric cancer cells. Additionally, Gal-9 reduced the phosphorylation of vascular endothelial growth factor receptor-3 (VEGFR-3) and insulin-like growth factor-1 receptor (IGF-1R). Furthermore, miRNA expression levels were markedly altered with Gal-9 treatment in vitro. In conclusion, Gal-9 suppressed the proliferation of human gastric cancer cells by inducing apoptosis. These findings suggest that Gal-9 could be a potential therapeutic target in the treatment of gastric cancer.
\end{abstract}

Correspondence to: Dr Tsutomu Masaki, Department of Gastroenterology and Neurology, Kagawa University School of Medicine, 1750-1 Ikenobe, Miki-cho, Kita-gun, Kagawa 761-0793, Japan

E-mail: tmasaki@med.kagawa-u.ac.jp

Abbreviations: Gal-9, galectin-9; CRDs, carbohydrate-recognition domains; miRNAs, microRNAs; CCK-8, Cell Counting Kit-8; phospho-RTKs, phosphorylated receptor tyrosine kinases; VEGR-3, vascular endothelial growth factor receptor-3; IGF-1R, insulin-like growth factor-1 receptor

Key words: caspase-cleaved keratin 18, gastric cancer, galectin-9, apoptosis, microRNAs, insulin-like growth factor 1 receptor, angiogenesis

\section{Introduction}

Gastric cancer is the second-leading cause of cancer-related mortality worldwide, and the prognosis of advanced gastric cancer remains poor (1). Despite advances in the treatment of gastric cancer, no standard palliative chemotherapy has been accepted for patients with metastatic gastric cancer $(2,3)$. Thus, there is a strong demand for new treatment options to address advanced stages of gastric cancer.

Galectins are classified according to their carbohydrate-recognition domain (CRD) and are subdivided into three groups: prototype galectins (galectins-1, -2, -7, -10, -13, and -14) and the chimera-type galectin (galectin-3) have a single CRD, while tandem-repeat-type galectins (galectins-4, $-8,-9$, and -12 ) have two CRDs joined by a flexible peptide linker (4-6). Galectin-9 (Gal-9) is a tandem-repeat-type galectin that is known for its key roles in eosinophil chemoattraction and activation (7-9). Similar to other galectins, Gal-9 regulates various cellular functions, such as aggregation, adhesion and apoptosis $(10,11)$. In recent studies, Gal-9 has been shown to induce apoptosis and thereby suppress cell proliferation and tumor growth in various hematologic malignancies, such as human melanoma $(12,13)$ and chronic myelogenous leukemia (14). Additionally, our recent studies revealed the antitumor effects of recombinant Gal-9 in various solid malignancies, such as hepatocellular carcinoma (15) and cholangiocarcinoma (16).

However, it is unclear whether Gal-9 suppresses gastric cancer cell proliferation. The aim of this study was to determine the effectiveness of Gal-9 against gastric cancer cell proliferation. Possible mechanisms associated with the antitumor effect of Gal-9 were also explored, including the activation of receptor tyrosine kinases, angiogenesis and microRNAs (miRNAs).

\section{Materials and methods}

Reagents and chemicals. Recombinant stable and mutant forms of human Gal-9 lacking the entire linker region were expressed and purified as described in our previous 
studies (17). Lactose, sucrose, and fetal bovine serum (FBS) were purchased from Wako Chemicals (Osaka, Japan). The Cell Counting Kit-8 (CCK-8) was purchased from Dojindo Laboratories (Kumamoto, Japan), and all other chemicals were obtained from Sigma Chemical (Tokyo, Japan).

Cell lines and culture. The human gastric cancer cell lines MKN1, MKN7, MKN45, and MKN74 were obtained from the Japanese Cancer Research Resources Bank (Tokyo, Japan). The cells were cultured in RPMI-1640 (Gibco Invitrogen, Carlsbad, CA, USA) supplemented with $10 \%$ heat-inactivated FBS and penicillin-streptomycin $(100 \mu \mathrm{g} / \mathrm{ml}$; Invitrogen) in a humidified atmosphere with $5 \% \mathrm{CO}_{2}$ at $37^{\circ} \mathrm{C}$.

Cell proliferation assay. We performed cell proliferation assays using a CCK-8 according to the manufacturer's instructions. Samples of each cell line $\left(1 \times 10^{4}\right.$ cells/well $)$ were seeded into a 96-well plate and cultured in $100 \mu \mathrm{l}$ of RPMI-1640 supplemented with 10\% FBS. Twenty-four hours after seeding, the cells were treated with $0.01,0.03,0.1$ or $0.3 \mu \mathrm{mol} / 1 \mathrm{Gal}-9$ in the culture medium and cultured for an additional $48 \mathrm{~h}$. To inhibit the galactoside binding of Gal-9, $30 \mathrm{mM}$ lactose was added. Sucrose was added as a control. CCK-8 reagent $(10 \mu \mathrm{l})$ was then added to each well, and the 96-well plate was incubated at $37^{\circ} \mathrm{C}$ for $3 \mathrm{~h}$. The absorbance of each well was measured at $450 \mathrm{~nm}$ using an auto-microplate reader.

Enzyme-linked immunosorbent assay (ELISA). Cell apoptosis assays were conducted by measuring the amounts of caspase-cleaved keratin-18 (CCK-18) using an M30 Apoptosense ELISA kit (Previva, Bromma, Sweden) (18). Samples of each cell type (5x $10^{3}$ cells/well) were seeded into a 96-well plate and cultured in $100 \mu \mathrm{l}$ of culture medium for $24 \mathrm{~h}$. The seeded cells were then treated with $0.3 \mu \mathrm{mol} / \mathrm{l} \mathrm{Gal}-9$. The remaining steps of the assay were carried out according to the manufacturer's instructions. The amounts of antigen in the controls and samples were calculated by interpolation from a standard curve.

Cell and tissue lysates. The preparation of lysates was conducted according to the methods previously described by us (19). All the steps were carried out at $4^{\circ} \mathrm{C}$. Protein concentrations were measured using a dye-binding protein assay based on the Bradford method (20).

Antibody arrays of phosphorylated receptor tyrosine kinases (phospho-RTKs). Human phospho-RTKs were assayed using human phospho-RTK array kits (R\&D Systems) according to the manufacturer's instructions. Briefly, phospho-RTK array membranes were blocked with $5 \%$ BSA/TBS $(0.01 \mathrm{M}$ Tris- $\mathrm{HCl}, \mathrm{pH}$ 7.6) for $1 \mathrm{~h}$ and incubated with $2 \mathrm{ml}$ of cell line lysates after normalization so that the amounts of proteins were equal. After 3 washes for 10 min each with TBS plus $0.1 \% \mathrm{v} / \mathrm{v}$ Tween-20 and 2 washes for $10 \mathrm{~min}$ with TBS alone to remove unbound materials, the membranes were incubated with anti-phospho-tyrosine-HRP antibody for $2 \mathrm{~h}$ at room temperature. Unbound HRP-conjugated antibody was washed out with $0.1 \%$ Tween-20 in TBS. Finally, each array membrane was exposed to X-ray film using a chemiluminescence detection system (Perkin-Elmer Co.).
Angiogenic profile analysis using an antibody array. A RayBio Human Angiogenesis Antibody Array (RayBiotech, Inc.) was used according to the manufacturer's protocol. This method is a dot-based assay enabling the detection and comparison of 20 angiogenesis-specific cytokines. Each array membrane was exposed to X-ray film using a chemiluminescence detection system (Perkin-Elmer Co.).

Analysis of a miRNA microarray. Samples of each cancer cell line were processed for total RNA extraction with an miRNeasy Mini kit (Qiagen, Venlo, The Netherlands) according to the manufacturer's instructions. Using an Agilent 2100 Bioanalyzer (Agilent Technologies), the RNA samples typically had $\mathrm{A}_{260 / 280}$ ratios between 1.9 and 2.1.

After measuring RNA levels with an RNA 6000 Nano kit (Agilent Technologies), the samples were labeled using a miRCURY Hy3/Hy5 Power labeling kit and were hybridized to a human miRNA Oligo chip 10, version 19.0 (Toray Industries, Tokyo, Japan). Scanning was conducted with a 3D-Gene Scanner 3000 (Toray Industries). 3D-Gene Extraction version 1.2 software (Toray Industries) was used to read the raw intensities of the images. To determine changes in miRNA expression between the Gal-9-treated and control samples, the raw data were analyzed via GeneSpring GX version 10.0 (Agilent Technologies). The samples were first normalized relative to 28S RNA and baseline-corrected to the median of all the samples.

Replicate data were consolidated into two groups, i.e., those from the galectin-9-treated cells and those from the control cells, and were organized using the hierarchical clustering and ANOVA functions in GeneSpring software. Hierarchical clustering was performed using the clustering function (condition tree) and the Euclidean correlation as a distance metric. A two-way ANOVA was conducted, and asymptotic p-values $(<0.05)$ were determined with no error corrections to identify the miRNAs that varied most prominently across the different groups. Only changes $>50 \%$ for at least one of the time-points for each sample were considered significant. All the analyzed data were globally normalized. The statistical significance of differentially expressed miRNAs was analyzed using Student's t-test.

Statistical analysis. All analyses were conducted using JMP8.0 (SAS Institute, Cary, NC, USA). Paired analyses between the groups were conducted using Student's t-test. A $p<0.05$ was considered to indicate a significant difference between groups.

\section{Results}

Gal-9 suppresses the proliferation of human gastric cancer cells. To evaluate the effect of Gal-9 on the in vitro growth of human gastric cancer cells, we examined the effect of Gal-9 on the proliferation of 4 gastric cancer cell lines, MKN1, MKN7, MKN45 and MKN74. Cells were grown in 10\% FBS and treated with $0.01,0.03,0.1$ or $0.3 \mu \mathrm{mol} / 1 \mathrm{Gal}-9$ or without Gal-9 as a control. The cell proliferation assay was conducted $48 \mathrm{~h}$ after the addition of the agents. As depicted in Fig. 1, treatment with Gal-9 led to a strong, dose-dependent inhibition of cell proliferation in the MKN74 and MKN45 cells, which are Gal-9-sensitive gastric cancer cell lines (Fig. 1). However, 


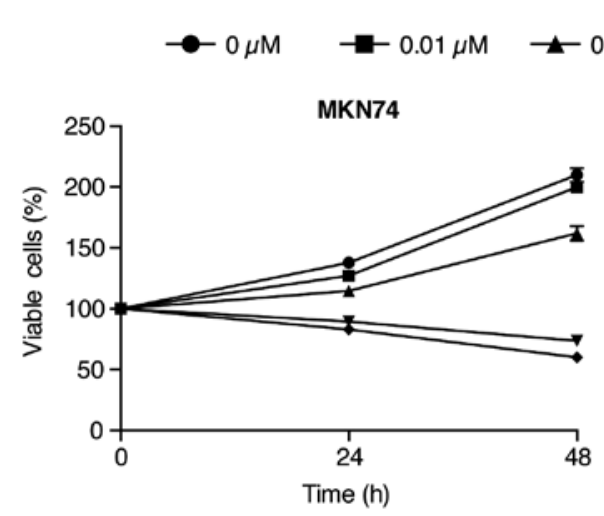

$0.3 \mu \mathrm{M}$
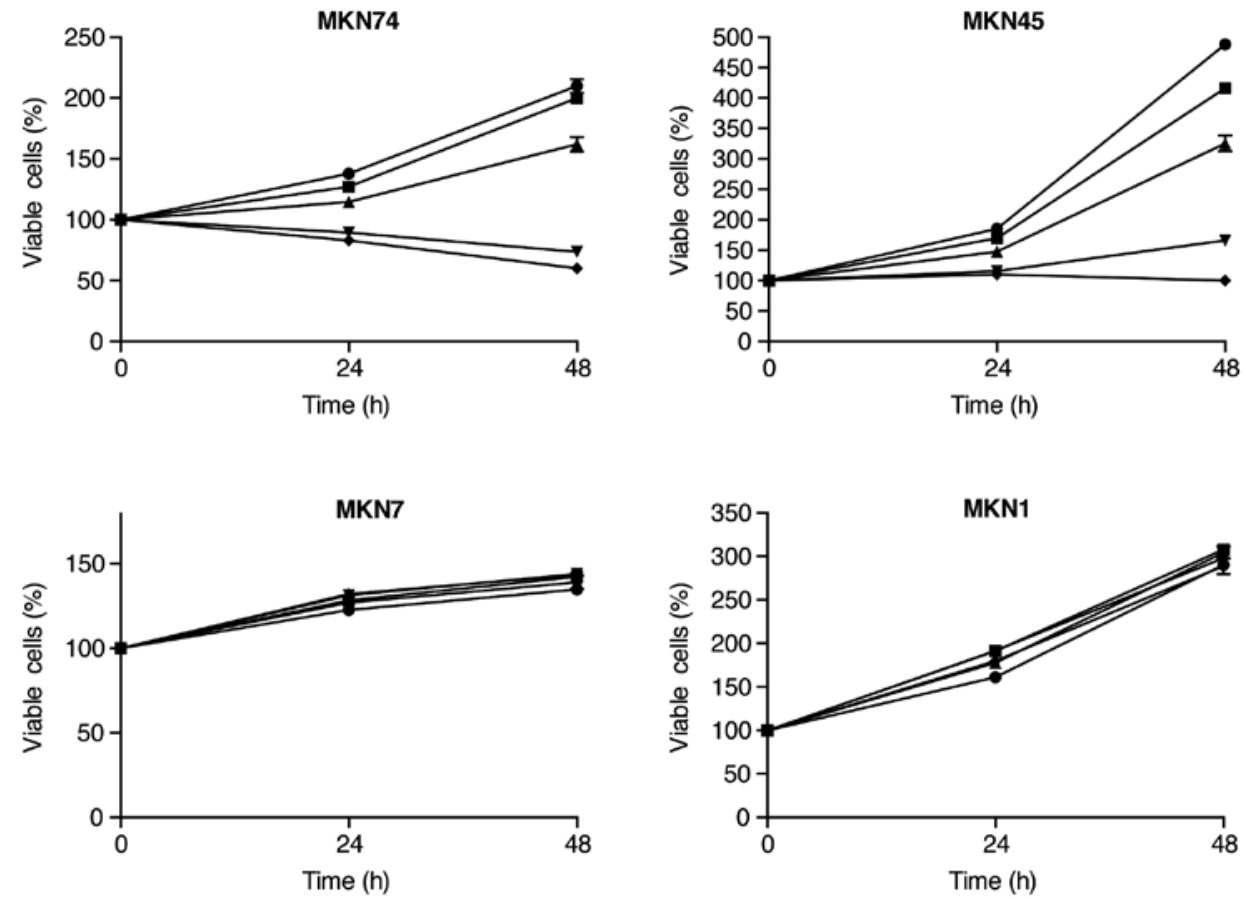

Figure 1. Galectin-9 (Gal-9) inhibits the proliferation of gastric cancer cell lines. MKN45, MKN74, MKN1, and MKN7 cells were seeded at 10,000 cells/well in 96-well plates, and Gal-9 $(0.01,0.030 .1$ or $0.3 \mu \mathrm{M})$ was added at time $0 \mathrm{~h}$. A Cell Counting Kit assay was conducted daily from time 0 to $48 \mathrm{~h}$. The mean cell number from three independent cultures is shown. The results are expressed as percentages of viable cells compared with the control. In the MKN45 and MKN74 cells, the conditions at 24 and $48 \mathrm{~h}$ in the cells treated with Gal-9 were significantly different compared with those in the control.

MKN74

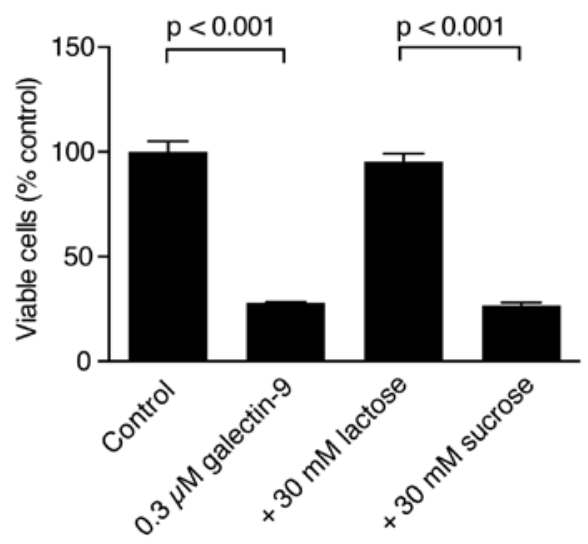

MKN45

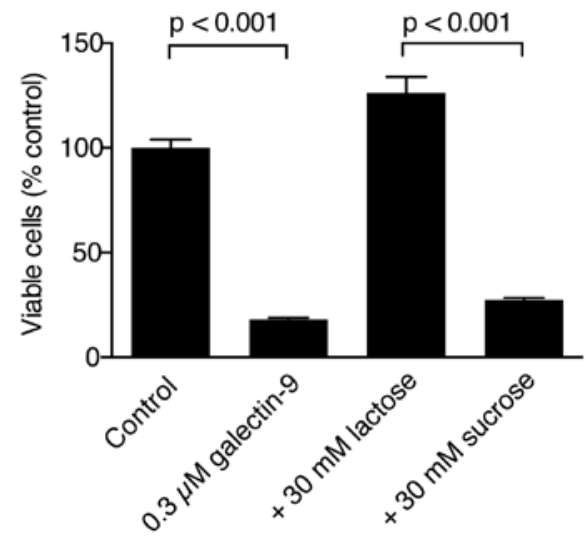

Figure 2. The antagonistic effect of lactose against galectin-9 (Gal-9) was assessed using a Cell Counting Kit assay. Cells were incubated with or without $30 \mathrm{mM}$ lactose in addition to $0.3 \mu \mathrm{M}$ Gal-9 for $48 \mathrm{~h}$. The effect of Gal-9 was antagonized by lactose, suggesting that the $\beta$-galactoside-binding nature of Gal-9 is essential for the activity. The p-values were calculated relative to the control.

no anti-proliferative effects of Gal-9 were detected in the MKN7 and MKN1 cells (Fig. 1).

The anti-proliferative effect of Gal-9 is inhibited by lactose in Gal-9-sensitive gastric cancer cells. The growth of the MKN74 and MKN45 cells was inhibited by Gal-9 with $30 \mathrm{mM}$ sucrose but not with $30 \mathrm{mM}$ lactose (Fig. 2). These data suggest that the binding of $\beta$-galactoside is essential for Gal-9 to inhibit the proliferation of the MKN74 and MKN45 cells, which are Gal-9-sensitive gastric cancer cells.
Gal-9 induces apoptosis in Gal-9-sensitive gastric cancer cells (MKN74 cells) but not Gal-9-resistant cells (MKN7 cells). To determine the mechanism(s) of the Gal-9 anti-proliferative effects, the level of caspase-cleaved cytokeratin 18 (CCK18), which is specifically produced during apoptosis, was measured using ELISAs in gastric cancer cells treated with $0.3 \mu \mathrm{M}$ Gal-9. Remarkably, Gal-9 increased the levels of CCK18 in Gal-9sensitive cells (MKN74 cells) but not in Gal-9-resistant cells (MKN7 cells) (Fig. 3). This result suggests that apoptosis is involved in Gal-9-induced cytostasis in the Gal-9-sensitive cells. 
MKN74

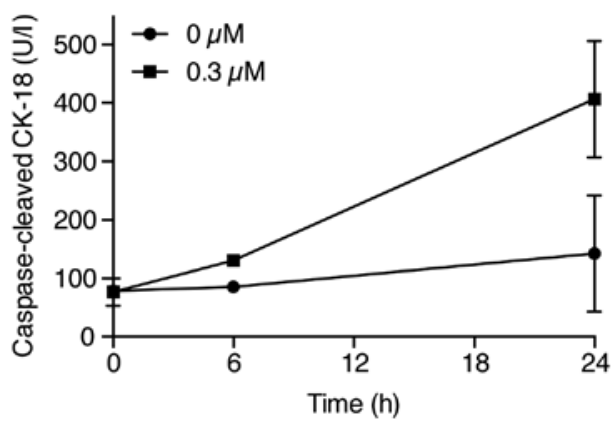

MKN7

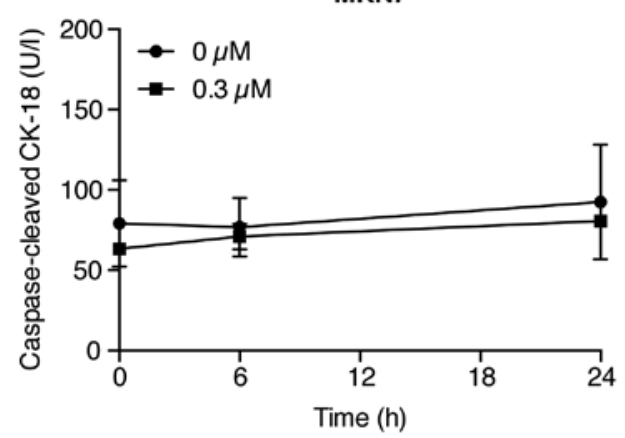

Figure 3. Galectin-9 (Gal-9) induced apoptosis in the MKN74 cells. Caspase-cleaved keratin 18 (CCK18) produced specifically in apoptosis was determined with an enzyme-linked immunosorbent assay (ELISA). Cells were incubated with or without $0.3 \mu \mathrm{M}$ Gal-9. Culture supernatants were used for the assay. The study was performed in triplicate.

A
\begin{tabular}{|c|c|c|c|c|c|c|c|c|c|c|c|}
\hline $\begin{array}{c}\text { Reference } \\
\text { spots }\end{array}$ & & & & & & & & & & & $\begin{array}{c}\text { Reference } \\
\text { spots }\end{array}$ \\
\hline EGF R & ErbB2 & ErbB3 & ErbB4 & FGF R1 & FGF R2a & FGF R3 & FGF R4 & Insulin R & IGF-1 R & Axl & Dtk \\
\hline Mer & HGF R & MSP R & PDGF Ra & PDGF Rb & SCF R & Flt-3 & M-CSF R & C-Ret & ROR1 & ROR2 & Tie-1 \\
\hline Tie-2 & TrkA & TrkB & TrkC & VEGF R1 & VEGF R2 & VEGF R3 & MuSK & EphA1 & EphA2 & EphA3 & EphA4 \\
\hline EphA6 & EphA7 & EphB1 & EphB2 & EphB4 & EphB6 & ALK & DDR1 & DDR2 & EphA5 & EphA10 & \\
\hline $\begin{array}{c}\text { Reference } \\
\text { Spots }\end{array}$ & & EphB3 & PYK & & & & & & & & PBS \\
\hline
\end{tabular}

B

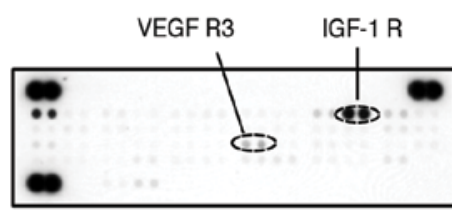

Gal-9 (-)

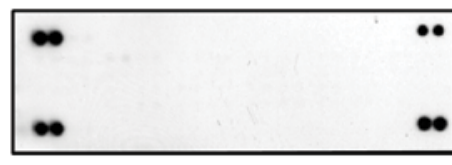

Gal-9 (-)
MKN74 cell

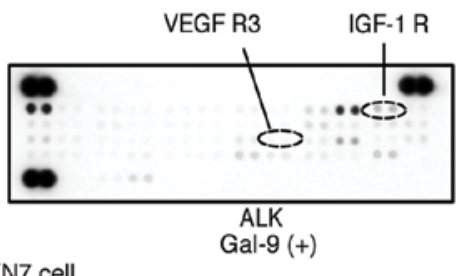

MKN7 cell

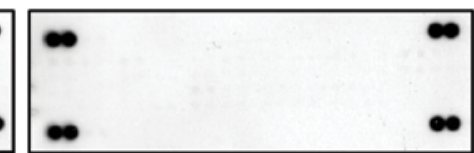

Gal-9 (+)
C

MKN74 cell

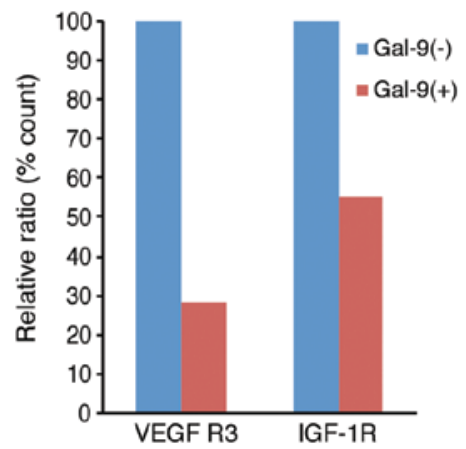

Figure 4. Effects of galectin-9 (Gal-9) on phospho-RTKs in MKN74 and MKN7 cells. (A) Template showing the location of tyrosine kinase antibody spotted onto human Phospho-RTK array. (B) Representative expression levels of various phospho-RTKs in MKN7 and MKN74 cells treated with or without Gal-9. Reduced expression levels of VEGFR and IGF-1R were detected in the MKN74 cells treated with Gal-9. (C) Densitometry analysis indicated that the ratios of the p-VEGFR-3 and p-IGF-1R spots of the Gal-9-treated cells to those of the untreated cells were 28.2 and $55.1 \%$, respectively.

Differences in phospho-RTKs in Gal-9-sensitive versus Gal-9-resistant gastric cancer cells treated with and without Gal-9. We next used a phospho-RTK array system to identify the key receptor tyrosine kinases (RTKs) associated with the anti-proliferative effects of Gal-9. Using this antibody array (Fig. 4A), we simultaneously screened the expression levels of 42 different RTKs activated in MKN74 and MKN7 cells with or without $0.3 \mu \mathrm{M}$ Gal-9. Gal-9 reduced the expression levels of vascular endothelial growth factor receptor-3 (VEGFR-3) and phosphorylated insulin-like-growth factor-1 receptor (IGF-1R) in the MKN74 cells (Fig. 4B). In contrast, no activated RTKs were upregulated in the Gal-9-resistant MKN1 cells.

Densitometric analyses revealed that the ratios of the p-VEGFR-3 and p-IGF-1R spots of the Gal-9-treated cells to those of the untreated cells were 28.2 and $55.1 \%$, respectively (Fig. 4C).

Effects of Gal-9 on angiogenesis in Gal-9-sensitive versus Gal-9-resistant gastric cancer cells. To examine the relationship between angiogenesis and Gal-9, an angiogenesis antibody array analysis was conducted regarding the antitumor effects of Gal-9 (Fig. 5A). Using the antibody array, we simultaneously screened the expression levels of 20 different angiogenesis-related proteins in MKN7 and MKN74 cells with or without Gal-9. The expression levels of interleukin-8 (IL-8), tissue inhibitor of metalloproteinase-1 (TIMP-1), TIMP-2, growth-related oncogene (GRO) and regulated-on-activation normal-T-cell-expressed and secreted (RANTES) were induced by Gal-9 treatment in the MKN74 cells as detected by 
A

\begin{tabular}{|l|c|c|c|c|c|c|c|}
\hline Positive & Positive & Negative & Negative & Angiogenin & EGF & ENA-78 & b FGF \\
\hline GRO & IFN- $\gamma$ & IGF-1 & IL-6 & IL-8 & LEPTIN & MCP-1 & PDGF-BB \\
\hline PIGF & RANTES & TGF-b1 & TIMP-1 & TIMP-2 & Thrombopoietin & VEGF & VEGF-D \\
\hline & & & & & & Negative & Positive \\
\hline
\end{tabular}

B

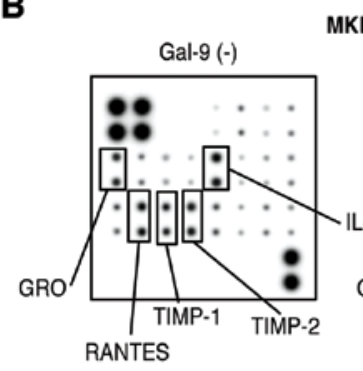

MKN74 cell

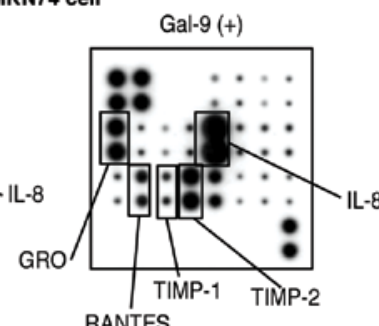

MKN7 cell

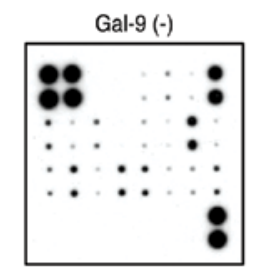

RANTES
C
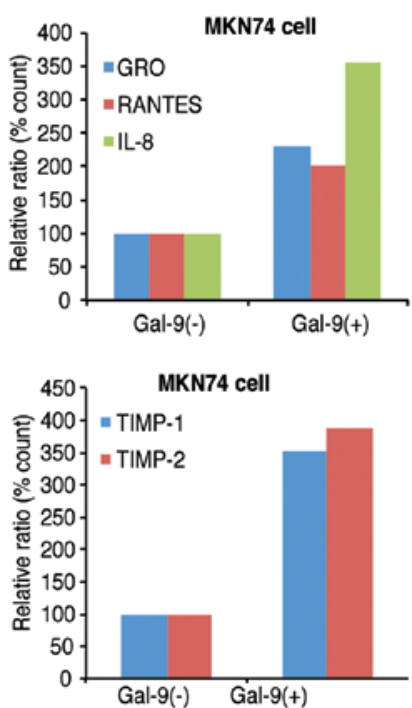

Figure 5. Effects of galectin-9 (Gal-9) on angiogenesis in the MKN74 and MKN7 cells. (A) Template depicting the location of antibodies for angiogenesisrelated proteins spotted onto a human angiogenesis array. (B) Representative expression levels of various antibodies for angiogenesis-related proteins in the MKN7 and MKN74 cells treated with or without Gal-9. Increased expression levels of IL-8, TIMP-1, TIMP-2, GRO, and RANTES were detected in the MKN74 cells treated with Gal-9. (C) Densitometry analysis indicated that the ratios of the IL-8, TIMP-1, TIMP-2, GRO, and RANTES spots of the Gal-9treated cells to those of the untreated cells were $356.1,355.3,389.36,231.1$ and $201.0 \%$, respectively.

the protein array (Fig. 5B). In the Gal-9-resistant MKN1 cells, no altered expression of angiogenesis molecules was detected with Gal-9 treatment.

Densitometric analyses indicated that the ratios of the IL-8, TIMP-1, TIMP-2, GRO, and RANTES spots of the Gal-9-treated cells to those of the untreated cells were 356.1, 355.3, 389.36, 231.1 and 201.0\%, respectively (Fig. 5C).

miRNA profiles of the cell lines treated in vitro with or without Gal-9. Using a custom microarray platform, we analyzed the in vitro expression levels of 2,555 human miRNA probes in gastric cancer cell lines that were treated with or without Gal-9. As presented in Table I, when the expression levels of miRNAs were measured in the MKN74 cells treated in vitro with or without $0.3 \mu \mathrm{mol} / 1 \mathrm{Gal}-9,153 \mathrm{miRNAs}$ were significantly upregulated $24 \mathrm{~h}$ after the Gal-9 treatment, whereas 18 miRNAs were downregulated.

An unsupervised hierarchical clustering analysis and a Pearson's correlation analysis indicated that MKN74 cells treated in vitro with Gal-9 clustered together and separately from the untreated MKN74 cells (Fig. 6).

\section{Discussion}

Gastric cancer is a very common disease worldwide and is the second most frequent cause of cancer-related deaths $(21,22)$. Although the overall incidence and mortality have dramatically declined over the past few decades, gastric cancer remains a major health problem (23). More than half of gastric cancer patients have lymph node metastasis when initially diagnosed or after surgical resection, which results in a poor prognosis (24-26). Patients with advanced stages of gastric cancer are treated with chemotherapy and radiation, either singly or in combination. However, none of these therapies is fully curative. Therefore, new therapeutic strategies are urgently required for the treatment of advanced gastric cancer. In recent studies, higher levels of Gal-9 expression were observed in patients without lymph-vascular invasion, lymph node metastases or distant metastases, and Gal-9 expression is closely associated with better survival rates in gastric cancer (27). Additionally, the downregulation of Gal-9 mRNA levels was observed in gastric cancer tissues; therefore, the loss of Gal-9 expression may be involved in the progression of gastric cancers (28). In the present study, we found that Gal-9 inhibited the proliferation of gastric cancer cell lines. In addition, we identified miRNAs associated with the antitumor effect of Gal-9 in gastric cancer.

Recombinant Gal-9 inhibits proliferation in various cancers such as melanoma (13) and chronic myelogenous leukemia (14) by inducing apoptosis. Our present results revealed that Gal-9 suppresses the proliferation of human gastric cancer cell lines in vitro. Gal-9 strongly inhibited cell proliferation in a dose-dependent manner in MKN45 and MKN74 cells but not in MKN1 and MKN7 cells. Notably, the histological type of the MKN74 and MKN7 cell lines is intestinal, while the MKN45 cells are a diffuse type, and the MKN1 cells are an adenosquamous carcinoma (29). Furthermore, the MKN7 and MKN1 cells were established from metastatic foci in the 
Table I. Changes in expression compared with untreated cells and chromosomal locations of miRNAs in MKN74 cells treated with galectin-9.

\begin{tabular}{|c|c|c|c|c|c|c|c|}
\hline & & & & miRNA & & P-value & \\
\hline miRNA & means $\pm \mathrm{SD}$ & P-value & & Upregulated & & & \\
\hline Upregulated & & & & nsa-miR-4/49- & $\begin{array}{r}3.87 \pm 0.722 \\
38+0.168\end{array}$ & $\begin{array}{l}0.00053 \\
0.00361\end{array}$ & $\begin{array}{l}19 \\
18\end{array}$ \\
\hline hsa-miR-204-3p & $12.41 \pm 3.011$ & 0.00023 & $9 q 21.12$ & hsa-miR-1469 & $\begin{array}{l}3.0 \pm 0.100 \\
3.8 \pm 0.652\end{array}$ & 0.00034 & $15 q 26.2$ \\
\hline hsa-miR-4688 & $11.27 \pm 2.983$ & 0.00032 & 11 & hsa-miR-1228-5p & $3.8 \pm 0.564$ & 0.00047 & 12 \\
\hline hsa-miR-4731-5p & $10.05 \pm 4.236$ & 0.00091 & 17 & hsa-miR-4463 & $3.78 \pm 0.131$ & 0.00074 & 6 \\
\hline hsa-miR-4459 & $8.36 \pm 2.17$ & 0.00016 & 5 & hsa-miR-4505 & $3.73 \pm 0.418$ & 0.00081 & 14 \\
\hline hsa-miR-4730 & $7.78 \pm 2.432$ & 0.00406 & 17 & hsa-miR-1915-3p & $3.72 \pm 1.571$ & 0.00219 & $10 \mathrm{p} 12.31$ \\
\hline hsa-miR-4294 & $7.54 \pm 3.654$ & 0.00164 & 10 & hsa-miR-4763-3p & $3.7 \pm 0.411$ & 0.00186 & 22 \\
\hline hsa-miR-3196 & $7.39 \pm 2.829$ & 0.00191 & 20 & hsa-miR-491-5p & $3.69 \pm 0.866$ & 0.00014 & $9 p 21.3$ \\
\hline hsa-miR-3648 & $7.32 \pm 1.06$ & 0.00049 & 21 & hsa-miR-4651 & $3.66 \pm 0.884$ & 0.00136 & 7 \\
\hline hsa-miR-4687-3p & $6.74 \pm 1.938$ & 0.00011 & 11 & hsa-miR-4435 & $3.62 \pm 1.308$ & 0.0397 & 2 \\
\hline hsa-miR-3197 & $6.46 \pm 1.153$ & 0.00408 & 21 & hsa-miR-1275 & $3.62 \pm 1.031$ & 0.00237 & 6 \\
\hline hsa-miR-4530 & $6.35 \pm 0.738$ & 0.00058 & 19 & hsa-miR-3180 & $3.53 \pm 1.989$ & 0.00998 & 16 \\
\hline hsa-miR-638 & $6.33 \pm 1.676$ & 0.0023 & $19 \mathrm{p} 13.2$ & hsa-miR-31-5p & $3.44 \pm 1.15$ & 0.00019 & $9 \mathrm{p} 21.3$ \\
\hline hsa-miR-1908 & $6.31 \pm 1.595$ & 0.00116 & 11 & hsa-miR-1909-3p & $3.34 \pm 0.825$ & 0.00498 & $19 \mathrm{p} 13.3$ \\
\hline hsa-miR-4442 & $6.28 \pm 1.781$ & 0.00281 & 3 & hsa-miR-3620-5p & $3.3 \pm 0.472$ & 0.00182 & 1 \\
\hline hsa-miR-4488 & $6.19 \pm 1.839$ & 0.00057 & 11 & hsa-miR-149-3p & $3.21 \pm 0.307$ & 0.00355 & $2 q 37.3$ \\
\hline hsa-miR-6125 & $6.16 \pm 0.699$ & 0.00048 & 12 & hsa-miR-4725-3p & $3.18 \pm 0.711$ & 0.00036 & 17 \\
\hline hsa-miR-4787-5p & $5.98 \pm 1.567$ & 0.00031 & 3 & hsa-miR-132-3p & $3.17 \pm 2.048$ & 0.00242 & $17 \mathrm{p} 13.3$ \\
\hline hsa-miR-6088 & $5.79 \pm 1.124$ & 0.00091 & 19 & hsa-miR-1587 & $3.13 \pm 0.557$ & 0.0024 & Xp11.4 \\
\hline hsa-miR-4466 & $5.78 \pm 1.562$ & 0.00633 & 6 & hsa-miR-4327 & $3.12 \pm 0.843$ & 0.0008 & 21 \\
\hline hsa-miR-3621 & $5.6 \pm 1.271$ & 0.0008 & 9 & hsa-miR-4726-5p & $3.12 \pm 0.454$ & 0.00084 & 17 \\
\hline hsa-miR-1237-5p & $5.6 \pm 1.902$ & 0.00142 & 11 & hsa-miR-1247-3p & $3.11 \pm 1.069$ & 0.02297 & $14 q 32.31$ \\
\hline hsa-miR-3940-5p & $5.54 \pm 1.068$ & 0.00106 & 19 & hsa-miR-486-3p & $3.1 \pm 0.267$ & 0.01475 & $8 \mathrm{p} 11.21$ \\
\hline hsa-miR-1227-5p & $5.52 \pm 1.785$ & 0.01023 & 19 & hsa-miR-1268b & $3.1 \pm 0.561$ & 0.00049 & 17 \\
\hline hsa-miR-4792 & $5.49 \pm 1.065$ & 0.0012 & 3 & hsa-miR-4497 & $3.08 \pm 0.395$ & 0.00092 & 12 \\
\hline hsa-miR-4508 & $5.41 \pm 0.595$ & 0.00019 & 15 & hsa-miR-642b-3p & $3.06 \pm 0.565$ & 0.00667 & 19 \\
\hline hsa-miR-3665 & $5.4 \pm 1.682$ & 0.00066 & 13 & hsa-miR-937-5p & $3.06 \pm 0.337$ & 0.005 & $8 q 24.3$ \\
\hline hsa-miR-2861 & $5.38 \pm 1.946$ & 0.00057 & 9 & hsa-miR-4728-5p & $3.03 \pm 1.161$ & 0.04874 & 17 \\
\hline hsa-miR-6126 & $5.36 \pm 1.517$ & 0.00735 & 16 & hsa-miR-365a-5p & $3.03 \pm 0.216$ & 0.00296 & $16 \mathrm{p} 13.12$ \\
\hline hsa-miR-5787 & $5.29 \pm 0.798$ & 0.00049 & 3 & hsa-miR-3180-3p & $3.01 \pm 0.606$ & 0.00032 & 16 \\
\hline hsa-miR-3656 & $5.15 \pm 1.083$ & 0.00053 & 11 & hsa-miR-675-5p & $2.97 \pm 1.027$ & 0.02744 & $11 \mathrm{p} 15.5$ \\
\hline hsa-miR-6075 & $5.14 \pm 1.757$ & 0.00036 & 5 & hsa-miR-4656 & $2.89 \pm 0.275$ & 0.00358 & 7 \\
\hline hsa-miR-1246 & $5.08 \pm 1.896$ & 0.03458 & $2 \mathrm{q} 31.1$ & hsa-miR-4270 & $2.83 \pm 0.615$ & 0.01617 & 3 \\
\hline hsa-miR-1229-5p & $4.92 \pm 1.854$ & 0.00022 & 5 & hsa-miR-5001-5p & $2.83 \pm 0.452$ & 0.01792 & 2 \\
\hline hsa-miR-4667-5p & $4.84 \pm 0.891$ & 0.00294 & 9 & hsa-miR-4257 & $2.81 \pm 0.263$ & 0.00051 & 1 \\
\hline hsa-miR-4756-5p & $4.68 \pm 4.77$ & 0.00762 & 20 & hsa-miR-4450 & $2.79 \pm 1.073$ & 0.01547 & 4 \\
\hline hsa-miR-6132 & $4.63 \pm 0.546$ & 0.00712 & 7 & hsa-miR-4507 & $2.79 \pm 0.356$ & 0.01068 & 14 \\
\hline hsa-miR-1268a & $4.63 \pm 0.402$ & 0.00071 & $15 q 11.2$ & hsa-miR-3937 & $2.77 \pm 1.063$ & 0.00578 & $\mathrm{X}$ \\
\hline hsa-miR-6085 & $4.28 \pm 1.456$ & 0.00273 & 15 & hsa-miR-513a-5p & $2.74 \pm 0.442$ & 0.023 & $\mathrm{Xq} 27.3$ \\
\hline hsa-miR-4484 & $4.17 \pm 1.354$ & 0.01331 & 10 & hsa-miR-1202 & $2.7 \pm 0.082$ & 0.00084 & 6 \\
\hline hsa-miR-652-5p & $4.15 \pm 0.76$ & 0.001 & $\mathrm{Xq} 23$ & hsa-miR-760 & $2.69 \pm 0.634$ & 0.0243 & $1 \mathrm{p} 22.1$ \\
\hline hsa-miR-4800-5p & $4.1 \pm 0.03$ & 0.02576 & 4 & hsa-miR-4638-3p & $2.67 \pm 0.394$ & 0.01986 & 5 \\
\hline hsa-miR-6131 & $4.08 \pm 0.446$ & 0.02093 & 5 & hsa-miR-5585-3p & $2.67 \pm 1.341$ & 0.00679 & $1 \mathrm{p} 35.2$ \\
\hline hsa-miR-6724-5p & $4.07 \pm 1.875$ & 0.0041 & 21 & hsa-miR-671-5p & $2.66 \pm 0.892$ & 0.00623 & $7 q 36.1$ \\
\hline hsa-miR-4745-5p & $4.04 \pm 0.883$ & 0.01705 & 19 & hsa-miR-4655-5p & $2.65 \pm 0.38$ & 0.00198 & 7 \\
\hline hsa-miR-642a-3p & $4 \pm 0.901$ & 0.0114 & $19 q 13.32$ & hsa-miR-212-3p & $2.64 \pm 0.448$ & 0.02006 & $17 \mathrm{p} 13.3$ \\
\hline hsa-miR-1973 & $3.97 \pm 0.422$ & 0.00364 & 4 & hsa-miR-4299 & $2.56 \pm 1.727$ & 0.01568 & 11 \\
\hline hsa-miR-663a & $3.88 \pm 0.336$ & 0.00185 & 20p11.1 & hsa-miR-4706 & $2.54 \pm 0.781$ & 0.00115 & 14 \\
\hline
\end{tabular}

Table I. Continued.

\section{Table I. Continued.}

Fold

Fo

treated/control) Chromosoma

hsc . 
Table I. Continued.

\begin{tabular}{|c|c|c|c|}
\hline miRNA & $\begin{array}{c}\text { Fold } \\
\text { (treated/control) } \\
\text { means } \pm \mathrm{SD}\end{array}$ & P-value & $\begin{array}{c}\text { Chromosomal } \\
\text { localization }\end{array}$ \\
\hline \multicolumn{4}{|l|}{ Upregulated } \\
\hline hsa-miR-132-5p & $2.52 \pm 0.469$ & 0.01826 & $17 \mathrm{p} 13.3$ \\
\hline hsa-miR-4722-5p & $2.49 \pm 0.116$ & 0.01955 & 16 \\
\hline hsa-miR-3135b & $2.48 \pm 0.096$ & 0.00061 & 6 \\
\hline hsa-miR-4732-5p & $2.48 \pm 0.216$ & 0.00737 & 17 \\
\hline hsa-miR-4758-5p & $2.46 \pm 0.487$ & 0.0002 & 20 \\
\hline hsa-miR-2392 & $2.4 \pm 0.749$ & 0.01092 & 14 \\
\hline hsa-miR-4449 & $2.37 \pm 0.582$ & 0.04587 & 4 \\
\hline hsa-miR-29a-3p & $2.36 \pm 0.685$ & 0.00438 & $7 q 32.3$ \\
\hline hsa-miR-6722-3p & $2.34 \pm 0.282$ & 0.00175 & 9 \\
\hline hsa-miR-3714 & $2.31 \pm 0.186$ & 0.03306 & 3 \\
\hline hsa-miR-744-5p & $2.3 \pm 1.104$ & 0.02676 & $17 \mathrm{p} 12$ \\
\hline hsa-miR-5006-5p & $2.23 \pm 0.694$ & 0.01224 & 13 \\
\hline hsa-miR-3141 & $2.22 \pm 0.677$ & 0.00299 & 5 \\
\hline hsa-miR-1185-1-3p & $2.21 \pm 0.698$ & 0.03128 & 14 \\
\hline hsa-miR-4436b-5p & $2.19 \pm 0.712$ & 0.01295 & 2 \\
\hline hsa-miR-4417 & $2.14 \pm 0.536$ & 0.00643 & 1 \\
\hline hsa-miR-5196-5p & $2.13 \pm 0.42$ & 0.00448 & 19 \\
\hline hsa-miR-296-5p & $2.12 \pm 0.383$ & 0.00725 & $20 q 13.32$ \\
\hline hsa-miR-6722-5p & $2.11 \pm 0.255$ & 0.01874 & 9 \\
\hline hsa-miR-614 & $2.09 \pm 0.597$ & 0.00179 & $12 \mathrm{p} 13.1$ \\
\hline hsa-miR-3678-3p & $2.08 \pm 0.805$ & 0.04442 & 17 \\
\hline hsa-miR-1914-3p & $2.03 \pm 0.474$ & 0.02587 & $20 q 13.33$ \\
\hline hsa-miR-4640-5p & $2.03 \pm 0.371$ & 0.03783 & 6 \\
\hline hsa-miR-4498 & $2.03 \pm 0.522$ & 0.04462 & 12 \\
\hline hsa-miR-194-5p & $1.97 \pm 0.588$ & 0.00849 & $1 q 41$ \\
\hline hsa-miR-29b-1-5p & $1.97 \pm 0.34$ & 0.00444 & $7 q 32.3$ \\
\hline hsa-miR-4695-5p & $1.95 \pm 0.352$ & 0.00097 & 1 \\
\hline hsa-miR-4707-5p & $1.93 \pm 0.2$ & 0.04286 & 14 \\
\hline hsa-miR-4690-5p & $1.92 \pm 0.098$ & 0.01814 & 11 \\
\hline hsa-miR-92b-5p & $1.91 \pm 0.499$ & 0.00537 & $1 q 22$ \\
\hline hsa-miR-4465 & $1.9 \pm 0.148$ & 0.00753 & 6 \\
\hline hsa-miR-3679-3p & $1.88 \pm 0.185$ & 0.00101 & 2 \\
\hline hsa-miR-711 & $1.87 \pm 0.536$ & 0.0124 & 3 \\
\hline hsa-miR-3185 & $1.84 \pm 0.161$ & 0.01036 & 17 \\
\hline hsa-miR-192-5p & $1.83 \pm 0.464$ & 0.02096 & $11 \mathrm{q} 13.1$ \\
\hline hsa-miR-370 & $1.82 \pm 0.547$ & 0.02131 & $14 q 32.2$ \\
\hline hsa-miR-658 & $1.81 \pm 0.577$ & 0.03598 & $22 q 13.1$ \\
\hline hsa-miR-222-3p & $1.76 \pm 0.614$ & 0.01237 & Xp11.3 \\
\hline hsa-miR-3195 & $1.71 \pm 0.131$ & 0.02378 & 20 \\
\hline hsa-miR-557 & $1.67 \pm 0.415$ & 0.01678 & $1 \mathrm{q} 24.2$ \\
\hline hsa-miR-221-3p & $1.59 \pm 0.406$ & 0.03976 & Xp11.3 \\
\hline hsa-miR-4634 & $1.54 \pm 0.367$ & 0.04868 & 5 \\
\hline hsa-miR-1225-5p & $1.52 \pm 0.189$ & 0.03676 & $16 \mathrm{p} 13.3$ \\
\hline hsa-miR-3609 & $1.52 \pm 0.002$ & 0.0084 & 7 \\
\hline hsa-miR-30c-1-3p & $1.48 \pm 0.065$ & 0.00171 & $1 \mathrm{p} 34.2$ \\
\hline hsa-miR-6515-3p & $1.45 \pm 0.106$ & 0.0161 & 19 \\
\hline hsa-miR-21-3p & $1.44 \pm 0.343$ & 0.02759 & $17 q 23.1$ \\
\hline hsa-miR-3144-5p & $1.44 \pm 0.124$ & 0.00824 & 6 \\
\hline hsa-miR-22-3p & $1.41 \pm 0.028$ & 0.01301 & $17 \mathrm{p} 13.3$ \\
\hline
\end{tabular}

Table I. Continued.

\begin{tabular}{lccc}
\hline & Fold & & \\
& & & \\
miRNA & $\begin{array}{c}\text { Chromosomal } \\
\text { means } \pm \text { SD }\end{array}$ & P-value & localization \\
\hline Upregulated & & & \\
hsa-miR-622 & $1.38 \pm 0.072$ & 0.01576 & $13 \mathrm{q} 31.3$ \\
hsa-miR-4650-3p & $1.38 \pm 0.096$ & 0.00266 & $7 \mathrm{q} 11.21$ \\
hsa-miR-877-5p & $1.38 \pm 0.156$ & 0.02297 & $6 \mathrm{p} 21.33$ \\
hsa-miR-660-5p & $1.3 \pm 0.247$ & 0.03583 & $\mathrm{Xp} 11.23$ \\
hsa-miR-3907 & $1.25 \pm 0.128$ & 0.01567 & 7 \\
hsa-miR-3161 & $1.24 \pm 0.009$ & 0.00212 & 11 \\
hsa-miR-4714-3p & $1.24 \pm 0.04$ & 0.04315 & 15 \\
hsa-miR-532-5p & $1.22 \pm 0.135$ & 0.01241 & $\mathrm{Xp} 11.23$ \\
Downregulated & & & \\
hsa-miR-30d-3p & $0.36 \pm 0.137$ & 0.01586 & $8 \mathrm{q} 24.22$ \\
hsa-miR-4785 & $0.44 \pm 0.144$ & 0.04552 & 2 \\
hsa-miR-4521 & $0.46 \pm 0.185$ & 0.02384 & 17 \\
hsa-miR-4722-3p & $0.5 \pm 0.171$ & 0.03034 & 16 \\
hsa-miR-4683 & $0.56 \pm 0.089$ & 0.01651 & 10 \\
hsa-miR-200b-5p & $0.58 \pm 0.137$ & 0.01679 & $1 \mathrm{p} 36.33$ \\
hsa-miR-345-5p & $0.6 \pm 0.19$ & 0.04389 & $14 \mathrm{q} 32.2$ \\
hsa-miR-590-5p & $0.6 \pm 0.077$ & 0.00326 & $7 \mathrm{q} 11.23$ \\
hsa-miR-103a-2-5p & $0.61 \pm 0.116$ & 0.0355 & $20 \mathrm{p} 13$ \\
hsa-miR-761 & $0.65 \pm 0.017$ & 0.0427 & 1 \\
hsa-miR-5692c & $0.65 \pm 0.132$ & 0.01502 & 5 \\
hsa-miR-299-3p & $0.68 \pm 0.02$ & 0.03763 & $14 \mathrm{q} 32.31$ \\
hsa-miR-126-5p & $0.69 \pm 0.079$ & 0.00758 & $9 \mathrm{q} 34.3$ \\
hsa-miR-4301 & $0.7 \pm 0.152$ & 0.03201 & 11 \\
hsa-miR-4522 & $0.72 \pm 0.161$ & 0.03506 & 17 \\
hsa-miR-627 & $0.74 \pm 0.034$ & 0.00686 & $15 \mathrm{q} 15.1$ \\
hsa-miR-1323 & $0.75 \pm 0.066$ & 0.04283 & $19 \mathrm{q} 13.42$ \\
hsa-miR-2681-5p & $0.76 \pm 0.055$ & 0.03387 & 13 \\
\hline miRNAs, microRNAs; SD & standard deviation. & \\
\hline & & & \\
\hline
\end{tabular}

lymph nodes $(29,30)$, whereas the MKN74 and MKN45 cells were derived from liver metastases (29,30). Accordingly, these data suggest that the liver metastatic type of gastric cancer cells (MKN74 and MKN45 cells) are more sensitive to Gal-9 treatment compared with the lymph node metastatic type of cells (MKN7 and MKN1 cells), regardless of their respective histological differentiation. These results suggest that Gal-9 may be a potential targeting moiety useful in distant metastasis in the advanced stages of gastric cancer.

The cleavage of cytokeratin by caspase (CCK18) occurs as an early event during apoptosis following the activation of apoptosis executioners, particularly effector caspases. However, cytokeratin remains intact during other types of cell death, such as autophagy or necrosis (31). In the present study, Gal-9 increased the levels of CCK18 in the MKN74 cells, which are sensitive to Gal-9, but not the MKN1 cells, which are resistant to Gal-9. These data indicate that Gal-9 


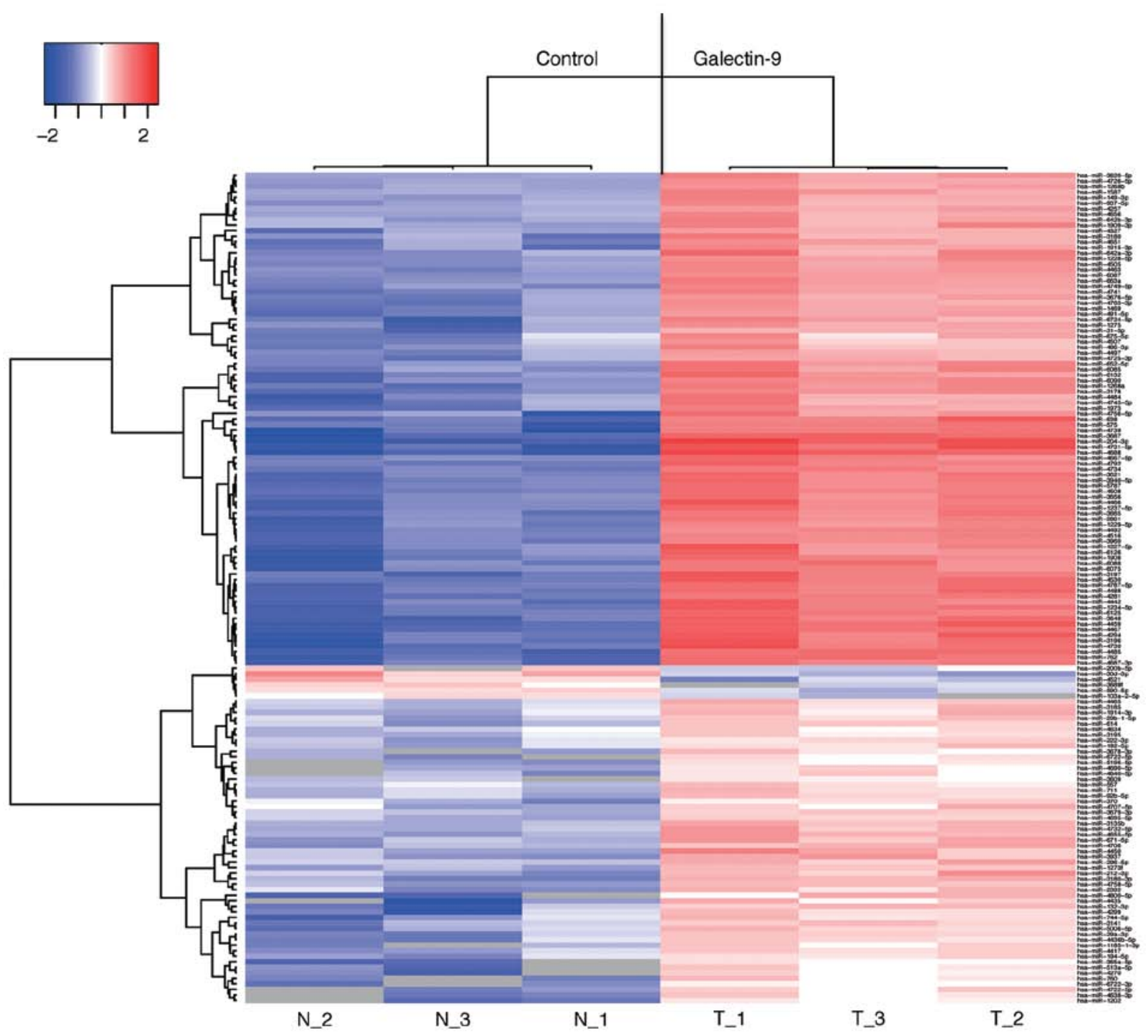

Figure 6. Hierarchical clustering of the MKN74 cells with or without galectin-9 (Gal-9) treatment. MKN74 cells were clustered according to the expression profiles of 171 miRNAs that were differentially expressed between the treated and untreated MKN74 cells. The analyzed samples are in columns, and the miRNAs are presented in rows. The miRNA clustering tree is shown on the left, and the sample-clustering tree is on the top. The color scale on the top illustrates the relative expression levels of miRNAs; red represents a high expression level, and blue represents a low expression level.

suppresses the proliferation of Gal-9-sensitive gastric cancer cells by inducing apoptosis.

Since the discovery of these proteins, RTKs have been investigated as key regulators of the proliferation, differentiation, and metastasis of gastric cancer cells (32). Our present study used phospho-RTK arrays to demonstrate that Gal-9 treatment reduced the expression levels of IGF-1R and VEGFR-3 in Gal-9-sensitive cells (MKN74) when compared with those in Gal-9-resistant cells (MKN7). IGF-1R is involved in cell proliferation and the prevention of apoptosis $(32,33)$. Galamb et al found via immunohistochemistry that IGF-1R was overexpressed in gastric cancer tissues when compared with normal mucosa (34). Additionally, the mRNA expression levels tended to be higher in cancer tissues than in normal mucosa (35). The overexpression of IGF-1R is associated with a poor response to chemotherapy and poor outcomes in stage I-IV gastric cancers (36). Gal-9 may reduce the expression levels of phospho-IGF-1R in gastric cancer and thereby improve chemosensitivity and the disease prognosis.
Galectins are important regulators of tumor progression that influence tumor cell transformation, immune escape and angiogenesis (4-6). Using angiogenesis-related protein arrays, we observed that IL-8, GRO, TIMP-1, TIMP-2 and RANTES were enhanced in Gal-9-sensitive gastric cancer cells. The enhanced expression of IL-8, in particular, may be associated with a poor prognosis, as determined by stage and histology, and indicate a more aggressive gastric cancer (37-39). These data suggest that Gal-9-sensitive gastric cancer cells immune to the antitumor effect of Gal-9 may produce angiogenesis-related proteins and thereby regulate angiogenesis in the in vivo microenvironment of gastric cancer tissues.

MicroRNAs, small non-coding RNA sequences, have been shown to regulate the development and progression of various cancers (40). To identify the miRNAs associated with the antitumor effects of Gal-9, we used miRNA expression arrays to determine variations in the miRNA profiles of the MKN74 cell line in cultures treated with or without Gal-9. The cluster-based analysis clearly demonstrated that Gal-9 
treatment affected the expression of numerous miRNAs. In the analysis, we selected sets of miRNAs with significantly altered expression levels with or without Gal-9 treatment. These altered miRNAs may provide clues to the molecular basis for the anticancer effects of Gal-9 in gastric cancer. Our data revealed that miR-204-3p and miR-1246 were upregulated in MKN74 cells treated with Gal-9. miR-204 targets Bcl-2, brain-derived neurotrophic factor (BDNF), SIRT1 and IGFBP5 expression and leads to apoptosis and cell cycle arrest in gastric cancer, neuroblastoma, ovarian cancer and papillary thyroid carcinoma. Furthermore, miR-204-3p has also been reported to act on fibronectin, inhibit the proliferation of hepatocellular carcinoma (HCC) endothelial cells and promote apoptosis (41). In contrast, miR-1246 has been reported to be a target of the p53 family, to inhibit Down syndrome-associated DYRK1A, and consequently activate NFTA1c and induce apoptosis (39). Our previous studies have shown that Gal-9 treatment upregulated miR-1246 in hepatocellular carcinoma (15) and cholangiocarcinoma (16), suggesting that miR-1246 may be associated with the antiproliferative effects of Gal-9 in various cancer cells.

In conclusion, our results revealed that Gal-9 suppresses human gastric cancer cell proliferation, possibly by inducing apoptosis, regulating RTK pathways and angiogenesis-related molecules, and altering miRNA expression profiles. These findings suggest that Gal-9 may be a novel therapeutic target in the treatment of gastric cancer.

\section{Acknowledgements}

We thank Ms.Ryoko Unose,Ms.Kana Ogawa, Ms. KayoHirose, Ms. Miwako Watanabe, Ms. Kayo Endo, and Ms. Noriko Murao for providing technical assistance.

\section{References}

1. Bray F, Jemal A, Grey N, Ferlay J and Forman D: Global cancer transitions according to the Human Development Index (2008-2030): A population-based study. Lancet Oncol 13: 790-801, 2012.

2. Lordick F and Siewert JR: Recent advances in multimodal treatment for gastric cancer: A review. Gastric Cancer 8: 78-85, 2005.

3. Bilici A: Treatment options in patients with metastatic gastric cancer: Current status and future perspectives. World J Gastroenterol 20: 3905-3915, 2014.

4. Thijssen VL, Heusschen R, Caers J and Griffioen AW: Galectin expression in cancer diagnosis and prognosis: A systematic review. Biochim Biophys Acta 1855: 235-247, 2015.

5. Wiersma VR, de Bruyn M, Helfrich W and Bremer E: Therapeutic potential of galectin-9 in human disease. Med Res Rev 33 (Suppl 1): E102-E126, 2013.

6. Fujihara S, Mori H, Kobara H, Rafiq K, Niki T, Hirashima M and Masaki T: Galectin-9 in cancer therapy. Recent Pat Endocr Metab Immune Drug Discov 7: 130-137, 2013.

7. Hirashima M: Ecalectin/galectin-9, a novel eosinophil chemoattractant: Its function and production. Int Arch Allergy Immunol 122 (Suppl 1): 6-9, 2000.

8. Matsumoto R, Matsumoto H, Seki M, Hata M, Asano Y, Kanegasaki S, Stevens RL and Hirashima M: Human ecalectin, a variant of human galectin-9, is a novel eosinophil chemoattractant produced by T lymphocytes. J Biol Chem 273: 16976-16984, 1998.

9. Matsushita N, Nishi N, Seki M, Matsumoto R, Kuwabara I, Liu FT, Hata Y, Nakamura T and Hirashima M: Requirement of divalent galactoside-binding activity of ecalectin/galectin-9 for eosinophil chemoattraction. J Biol Chem 275: 8355-8360, 2000 .
10. Saita N, Goto E, Yamamoto T, Cho I, Tsumori K, Kohrogi H, Maruo K, Ono T, Takeya M, Kashio Y, et al: Association of galectin-9 with eosinophil apoptosis. Int Arch Allergy Immunol 128: 42-50, 2002.

11. Asakura H, Kashio Y, Nakamura K, Seki M, Dai S, Shirato Y, Abedin MJ, Yoshida N, Nishi N, Imaizumi T, et al: Selective eosinophil adhesion to fibroblast via IFN-gamma-induced galectin-9. J Immunol 169: 5912-5918, 2002.

12. Kageshita T, Kashio Y, Yamauchi A, Seki M, Abedin MJ, Nishi N, Shoji H, Nakamura T, Ono T and Hirashima M: Possible role of galectin-9 in cell aggregation and apoptosis of human melanoma cell lines and its clinical significance. Int J Cancer 99: 809-816, 2002.

13. Kobayashi T, Kuroda J, Ashihara E, Oomizu S, Terui Y, Taniyama A, Adachi S, Takagi T, Yamamoto M, Sasaki N, et al: Galectin-9 exhibits anti-myeloma activity through JNK and p38 MAP kinase pathways. Leukemia 24: 843-850, 2010.

14. Kuroda J, Yamamoto M, Nagoshi H, Kobayashi T, Sasaki N, Shimura Y, Horiike S, Kimura S, Yamauchi A, Hirashima M, et al: Targeting activating transcription factor 3 by galectin- 9 induces apoptosis and overcomes various types of treatment resistance in chronic myelogenous leukemia. Mol Cancer Res 8: 994-1001, 2010.

15. Fujita K, Iwama H, Sakamoto T, Okura R, Kobayashi K, Takano J, Katsura A, Tatsuta M, Maeda E, Mimura S, et al: Galectin-9 suppresses the growth of hepatocellular carcinoma via apoptosis in vitro and in vivo. Int J Oncol 46: 2419-2430, 2015.

16. Kobayashi K, Morishita A, Iwama H, Fujita K, Okura R, Fujihara S, Yamashita T, Fujimori T, Kato K, Kamada H, et al: Galectin-9 suppresses cholangiocarcinoma cell proliferation by inducing apoptosis but not cell cycle arrest. Oncol Rep 34: 1761-1770, 2015

17. Nishi N, Itoh A, Fujiyama A, Yoshida N, Araya S, Hirashima M, Shoji $\mathrm{H}$ and Nakamura T: Development of highly stable galectins: Truncation of the linker peptide confers protease-resistance on tandem-repeat type galectins. FEBS Lett 579: 2058-2064, 2005.

18. Schutte B, Henfling M, Kölgen W, Bouman M, Meex S, Leers MP, Nap M, Björklund V, Björklund P, Björklund B, et al: Keratin 8/18 breakdown and reorganization during apoptosis. Exp Cell Res 297: 11-26, 2004.

19. Masaki T, Tokuda M, Yoshida S, Nakai S, Morishita A, Uchida N, Funaki T, Kita Y, Funakoshi F, Nonomura T, et al: Comparison study of the expressions of myristoylated alanine-rich $\mathrm{C}$ kinase substrate in hepatocellular carcinoma, liver cirrhosis, chronic hepatitis, and normal liver. Int J Oncol 26: 661-671, 2005.

20. Bradford MM: A rapid and sensitive method for the quantitation of microgram quantities of protein utilizing the principle of protein-dye binding. Anal Biochem 72: 248-254, 1976.

21. Hartgrink HH, Jansen EP, van Grieken $\mathrm{NC}$ and van de Velde CJ: Gastric cancer. Lancet 374: 477-490, 2009.

22. Kamangar F, Dores GM and Anderson WF: Patterns of cancer incidence, mortality, and prevalence across five continents: Defining priorities to reduce cancer disparities in different geographic regions of the world. J Clin Oncol 24: 2137-2150, 2006.

23. Siegel R, Naishadham D and Jemal A: Cancer statistics, 2013. CA Cancer J Clin 63: 11-30, 2013.

24. Abe N, Watanabe T, Suzuki K, Machida H, Toda H, Nakaya Y, Masaki T, Mori T, Sugiyama M and Atomi Y: Risk factors predictive of lymph node metastasis in depressed early gastric cancer. Am J Surg 183: 168-172, 2002.

25. Yamaguchi T, Sano T, Katai H, Sasako M and Maruyama K: Node-positive mucosal gastric cancer: A follow-up study. Jpn J Clin Oncol 31: 153-156, 2001

26. de Manzoni G, Verlato G, di Leo A, Guglielmi A, Laterza E, Ricci $\mathrm{F}$ and Cordiano C: Perigastric lymph node metastases in gastric cancer: Comparison of different staging systems. Gastric Cancer 2: 201-205, 1999.

27. Jiang J, Jin MS, Kong F, Cao D, Ma HX, Jia Z, Wang YP, Suo J and Cao X: Decreased galectin- 9 and increased Tim-3 expression are related to poor prognosis in gastric cancer. PLoS One 8: e81799, 2013

28. Yang J, Zhu L, Cai Y, Suo J and Jin J: Role of downregulation of galectin-9 in the tumorigenesis of gastric cancer. Int J Oncol 45: 1313-1320, 2014.

29. Yokozaki H: Molecular characteristics of eight gastric cancer cell lines established in Japan. Pathol Int 50: 767-777, 2000.

30. Motoyama T, Hojo $\mathrm{H}$ and Watanabe $\mathrm{H}$ : Comparison of seven cell lines derived from human gastric carcinomas. Acta Pathol Jpn 36: 65-83, 1986. 
31. Kramer G, Erdal H, Mertens HJ, Nap M, Mauermann J, Steiner G, Marberger M, Bivén K, Shoshan MC and Linder S: Differentiation between cell death modes using measurements of different soluble forms of extracellular cytokeratin 18. Cancer Res 64: 1751-1756, 2004.

32. Morishita A, Gong J and Masaki T: Targeting receptor tyrosine kinases in gastric cancer. World J Gastroenterol 20: 4536-4545, 2014.

33. Hilmi C, Larribere L, Giuliano S, Bille K, Ortonne JP, Ballotti R and Bertolotto C: IGF1 promotes resistance to apoptosis in melanoma cells through an increased expression of BCL2, BCL-X(L), and survivin. J Invest Dermatol 128: 1499-1505, 2008.

34. Numata K, Oshima T, Sakamaki K, Yoshihara K, Aoyama T, Hayashi T, Yamada T, Sato T, Cho H, Shiozawa M, et al: Clinical significance of IGF1R gene expression in patients with stage II/III gastric cancer who receive curative surgery and adjuvant chemotherapy with S-1. J Cancer Res Clin Oncol: Sep 3, 2015 (Epub ahead of print). http://dx.doi.org/10.1007/s00432-015-2039-6.

35. Galamb O, Sipos F, Molnar B, Szoke D, Spisak S and Tulassay Z: Evaluation of malignant and benign gastric biopsy specimens by mRNA expression profile and multivariate statistical methods. Cytometry B Clin Cytom 72: 299-309, 2007.
36. Ge J, Chen Z, Wu S, Chen J, Li X, Li J, Yin J and Chen Z: Expression levels of insulin-like growth factor-1 and multidrug resistance-associated protein-1 indicate poor prognosis in patients with gastric cancer. Digestion 80: 148-158, 2009.

37. Yamada S, Kato S, Matsuhisa T, Makonkawkeyoon L, Yoshida M, Chakrabandhu T, Lertprasertsuk N, Suttharat P, Chakrabandhu B, Nishiumi S, et al: Predominant mucosal IL-8 mRNA expression in non-cagA Thais is risk for gastric cancer. World J Gastroenterol 19: 2941-2949, 2013.

38. Lee KH, Bae SH, Lee JL, Hyun MS, Kim SH, Song SK and Kim HS: Relationship between urokinase-type plasminogen receptor, interleukin-8 gene expression and clinicopathological features in gastric cancer. Oncology 66: 210-217, 2004.

39. Lee KE, Khoi PN, Xia Y, Park JS, Joo YE, Kim KK, Choi SY and Jung YD: Helicobacter pylori and interleukin-8 in gastric cancer. World J Gastroenterol 19: 8192-8202, 2013.

40. Morishita A and Masaki T: miRNA in hepatocellular carcinoma. Hepatol Res 45: 128-141, 2015.

41. Cui ZH, Shen SQ, Chen ZB and Hu C: Growth inhibition of hepatocellular carcinoma tumor endothelial cells by miR-204-3p and underlying mechanism. World J Gastroenterol 20: 5493-5504, 2014. 